\title{
The Independent Inquiry into Child Sexual Abuse in the UK: reflecting on the mental health needs of victims and survivors
}

Antonina Ingrassia

\section{Summary}

The nature and extent of the sexual abuse of children and young people and the pervasiveness of inappropriate institutional responses to its occurrence continues to raise serious concerns. The work of the Inquiry is a powerful reminder of the role of mental health services in addressing the needs of victims and survivors.

\section{Declaration of interest}

None.

\section{Keywords}

Sexual abuse inquiry; mental health needs of victims and survivors; Truth Project.

\section{Copyright and usage}

(c) The Royal College of Psychiatrists 2018.
Antonina Ingrassia is a Consultant Child and Adolescent Psychiatrist at the South London and Maudsley NHS Trust. She is the clinical lead for the Children \& Young People's Health Partnership, an integrated community paediatric liaison team, looking at the physical and mental health needs of children with health conditions. She is committed to the delivery of effective mental health services for children and families, particularly to increasing access for disadvantaged and vulnerable groups.

\section{Introduction - the context for the Inquiry}

'The only conceivably worthy honour due to those harmed is to make changes that will save other people and other places from similar harm. ${ }^{1}$

The media's reporting of the Jimmy Savile case, uncovering predatory sexual abuse, perhaps on an unprecedented scale, and concerning institutional responses to it generated significant public interest. Since then, accounts of the involvement of high-profile individuals and organisations have continued to grab the headlines; alongside them, serious concerns about institutional responses have been highlighted in the Rotherham Inquiry, ${ }^{2}$ inspections of the Metropolitan Police ${ }^{3}$ and reviews of services provided by the National Health Service for looked after children and safeguarding. ${ }^{4}$

Not surprisingly, on 7 July 2014 the then Home Secretary Theresa May announced in Parliament the launch of an inquiry into historic allegations of child sexual abuse in the UK.

Similar inquiries have been undertaken in Scotland, in Jersey and Northern Ireland. In Australia, a Royal Commission was appointed to also inquire into institutional responses to child sexual abuse, a reminder of the global scale of this issue.

It is fair to say that the Inquiry has not had an easy journey, its work beset by the controversial resignation of the former Chair, Justice Goddard (already the third person resigning from the position), plagued by the exit of several counsel, scrutinised by the Home Affairs Select Committee and criticised over the engagement of survivors. In many ways these difficulties reflect the challenges of the Inquiry's ambitious brief but also perhaps mirror societal struggles in effectively confronting such a disconcerting topic because of its impact on values, beliefs and norms.

\section{The Truth Project - narratives of truth in talking about sexual abuse}

In October 2017 the Truth Project, one of the Inquiry's core projects, released its first report, ${ }^{5}$ a helpful prompt to reflect on the notion of 'truth' within this context. In the personal stories we find many chilling reports of the accounts of victims being covered up, twisted and mocked by abusers covering their tracks and institutions covering their backs.

Talking about sexual abuse is hard; intimidation can be used by perpetrators to discourage victims from sharing their experiences and in many situations the fear persists long after the abuse has stopped. Narratives of self-blame in individuals who have been abused are promoted by the self-serving narratives of perpetrators, 'it's your fault', 'you deserve it', 'you asked for it', within a web that is very difficult to disentangle. The grooming process often teaches and forces victims to lie and mislead others, a process that further isolates them. Inconsistent accounts are therefore not uncommon: fragmented descriptions may take years to shape into a coherent, if painful, narrative and often require a number of supportive structures to achieve this. To expect anything different is likely to put undue pressure on vulnerable individuals.

Then there is the problem of a culture of disbelief and scepticism among the very institutions which should protect and safeguard. 'Don't tell anyone, because they won't believe you anyway, ${ }^{6}$ the described experience of a victim of sexual abuse by the parish priest. This pervasive attitude, which undermines attempts to address concerns, was also encountered in the Truth Project as participants described institutional failures to follow-up disclosures, sometimes leading to continued abuse.

Engaging individuals who have suffered sexual abuse to bear witness to their experience can be problematic, for many reasons, but can it also be liberating? The work of the Australian Royal Commission and the Truth Project with victims and survivors indicates that, for some, the testimony had been part of a journey of recovery. Interesting parallels can be drawn with the work of the Truth and Reconciliation Commission in South Africa. As Kaminer et al illustrate, ${ }^{7}$ this is a complex issue and the role of truth commissions can only be considered an adjunct to, not a 
substitute for, appropriate therapeutic interventions by mental health services.

\section{Mental health needs of victims and survivors}

A literature review on the healthcare experiences of adult survivors ${ }^{8}$ shows a clear correlation between history of childhood sexual abuse and health, health behaviours and health outcomes, clearly highlighting the need for greater awareness of these issues among all healthcare professionals. The effect of adverse life events and childhood trauma on many leading causes of death is also well-known. ${ }^{9}$

Approaching the problem from a public health framework may also be helpful to inform better decisions about funding for prevention and treatment programmes, particularly when considering spending as compared with other complex public health issues such as obesity, smoking and drinking. Individuals affected by sexual abuse can present to a range of different health services including sexual health, emergency/urgent care, mental health, drug and alcohol services, general practitioners. A National Society for the Prevention of Cruelty to Children review ${ }^{10}$ conservatively estimates the annual cost of child sexual abuse as $£ 1.6 \mathrm{bn}$ in 2012; this is likely to be an underestimation.

Sexual abuse has also been associated with a range of long-term mental health difficulties in adulthood. ${ }^{11}$ In addition, many studies ${ }^{12,13}$ including a meta-analysis ${ }^{14}$ indicate that exposure to adverse childhood events, including sexual abuse, is a risk factor for the development of psychosis, lending strength to a multifactor model of psychosis acknowledging multiple elements of genetic and environmental risk. ${ }^{15}$

A total of $82 \%$ of the participants in the Truth Project reported mental health problems and mental health issues were quoted as the most common source of disability. Despite the availability of this body of research, the work of mental health services around sexual abuse is patchy, many still regarding this as an area of work that does not belong to the 'core' business of mental health.

Looking at the nature and availability of therapeutic services for sexually abused children and young people Allnock et al ${ }^{16}$ highlight that although therapeutic work was indeed carried out within Child and Adolescent Mental Health Service settings many struggled to adequately prioritise it. Shaw \& DeJong ${ }^{17}$ also point out that 'Child and adolescent mental health services have historically tended to regard child abuse and neglect as a social problem, requiring a social care solution'. These concerns are echoed in the findings of the Rotherham Inquiry: '... children and young people needed and wanted specialist counselling and support. They were unable to access services because of long waiting lists and gaps in services. ${ }^{2}$ DeJong ${ }^{18}$ further highlights how main stream services are not well set up to identify and address the mental health needs of young people who, having suffered abuse, may present with complex post-traumatic stress disorder, comorbidities, subthreshold presentation and symptoms that do not neatly fit existing diagnostic criteria. Similar issues are faced by adult survivors, many reporting negative experiences of mental health services; ${ }^{19}$ closer collaboration with voluntary services, advocated in a report by the Scottish Executive, ${ }^{20}$ may be a way to address these difficulties.

\section{What do mental health services need to do to improve their work with victims and survivors?}

Adult survivors often do not disclose abuse when seeking assistance, their experiences likely to be informed by previous encounters with people in authority whose responses may have been ill-informed, inadequate and, at times, harmful. Therefore, the responsibility rests with the sensitive and well-informed clinician's ability to see past the 'presenting problem' to proactively and routinely ask about sexual abuse. Practitioners' lack of skills and confidence in approaching the topic of sexual abuse with patients can be a significant barrier. The report by the Scottish Executive indicates that 'Many staff do not feel sufficiently confident in their skills or supported enough emotionally to be able to ask questions that might "open a can of worms". 20

In recognition of these issues the Mental Health Trusts Collaboration Project was commenced in July 2006, one of its main outcomes to embed sexual abuse as a core mental health issue by promoting routine exploration, establishing routes for therapeutic support and encouraging joint working with survivors. As highlighted by Louis Appleby in his introduction, one of the key messages from the evaluation of the Project and, potentially, a serious challenge to all mental health services is the 'need to change over the question from "What is wrong with this person?" to "What has happened to this person?"'21

The training and support of practitioners, as well as public education, remain crucial in the journey of improvement of mental health, indeed all health services so that professionals feel able to confidently and sensitively approach the topic of abuse. The testimony of a service user on the impact of the training on his care coordinator is a powerful endorsement of this approach: '[my care coordinator] is much more confident now in talking about abuse with me and so much more sensitive and empathic'. ${ }^{21}$

\section{Conclusions}

After many years I still remember a patient I saw during a duty shift in accident and emergency. I am not sure what or how I asked as this young woman in her twenties started sharing a detailed account of years of sexual abuse in her foster family as a child and the police's dismissal of her claims as an adult. The patient told me her story, thanked me for listening and left. She politely refused follow-up and did not meet criteria for compulsory admission. I felt useless.

A few more years of psychiatric practice helped me understand that my feelings might have given me an insight into the patient's own feelings of uselessness. And that taking the time to listen, even in a busy accident and emergency department, is a most powerful intervention.

In her opening statement for the Inquiry Justice Lovell encourages organisations to take a proactive stance. I believe that exhortation should reach all psychiatrists, indeed all healthcare professionals, to re-examine what we have done and what more can we do to support the needs of victims and survivors of sexual abuse.

Antonina Ingrassia, MBBS (Hons), FRCPsych, MSC, FHEA, Consultant Child and Adolescent Psychiatrist, South London and Maudsley NHS Trust, Lower Ground, Minerva House, 5 Montague Close, London SE1 9BB, UK. Email: anto.ingrassia@slam.nhs.uk

First received 13 Nov 2017, final revision 29 Mar 2018, accepted 11 May 2018

\section{References}

1 National Advisory Group on the Safety of Patients in England. A Promise to Learn - A Commitment to Act Improving the Safety of Patients in England. National Advisory Group on the Safety of Patients in England, 2013 (https:// assets.publishing.service.gov.uk/government/uploads/system/uploads/ attachment_data/file/226703/Berwick_Report.pdf).

2 Jay A. Independent Inquiry into Child Sexual Exploitation in Rotherham 19972013. Rotherham Metropolitan Borough Council, 2014 (https://www.rotherham.gov.uk/downloads/file/1407/independent inquiry_cse in rotherham). 
3 Her Majesty's Inspector of Constabulary. In Harm's Way: The Role of Police in Keeping Children Safe. HMIC, 2015 (https://www.justiceinspectorates.gov.uk/ hmicfrs/wp-content/uploads/in-harms-way.pdf)

4 Care Quality Commission. Not Seen, not Heard-A Review of the Arrangements for Child Safeguarding and Health Care for Looked After Children in England. CQC, 2016.

5 Independent Inquiry into Child Sexual Abuse. Victim and Survivor Voices from The Truth Project. IICSA, 2017 (https://www.iicsa.org.uk/document/victim-andsurvivor-voices-truth-project).

6 Royal Commission into Institutional Responses to Child Sexual Abuse. Royal Commission into Institutional Responses to Child Sexual Abuse. Interim report Volume 2. Commonwealth of Australia, 2014 (https://www.childabuseroyalcommission.gov.au/sites/default/files/file-list/final report - interim report volume_2.pdf).

7 Kaminer D, Stein DJ, Mbanga I, Zungu-Dirwayi N. The Truth and Reconciliation commission in South Africa: relation to psychiatric status and forgiveness among survivors of human rights abuses. Br J Psychiatry 2001; 178: 373-7.

8 Havig K. The healthcare experiences of adult survivors of child sexual abuse: a systematic review of evidence on sensitive practice. Trauma Violence Abuse 2008; 9: 19-33

9 Felitti VJ, Anda RF, Nordenberg D, Williamson DF, Spitz AM, Edwards V, et al. Relationship of childhood abuse and household dysfunction to many of the leading causes of death in adults. The Adverse Childhood Experiences (ACE) Study. Am J Prev Med 1998; 14: 245-58.

10 Saied-Tessier A. Estimating the Costs of Child Sexual Abuse in the UK. NSPCC 2014

11 Fergusson DM, Boden JM, Horwood LJ. Exposure to childhood sexual and physical abuse and adjustment in early adulthood. Child Abuse Neglect 2008; 32: 607-9.
12 Cutajar MC. Schizophrenia and other psychotic disorders in a cohort of sexually abused children. Arch Gen Psychiatry 2010; 67: 1114-9.

13 Bebbington $\mathrm{P}$, Jonas S, Kuipers E, King M, Cooper C, Brugha T, et al. Childhood sexual abuse and psychosis: data from a cross-sectional national psychiatric survey in England. Br J Psychiatry 2011; 199: 29-37.

14 Varese F. Childhood adversities increase the risk of psychosis: a meta-analysis of patient-control, prospective- and cross-sectional cohort studies. Schizophr Bull 2012; 38: 661-71.

15 Freedman R. Investigating trauma as a risk factor for psychosis. Schizophr Bull 2017: 43: 1-2.

16 Allnock D with Bunting L, Price A, Morgan-Klein N, Ellis J, Radford L, et al. Sexual Abuse and Therapeutic Services for Children and Young People. The Gap Between Provision and Need. NSPCC, 2009.

17 Shaw M, De Jong M. Child abuse and neglect: a major public health issue and the role of child and adolescent mental health services. Psychiatrist 2012; 36: $321-5$.

18 DeJong M. Some reflections on the use of psychiatric diagnosis in the looked after or 'in care' child population. Clin Child Psychol Psych 2010; 15: 589-99.

19 Smith N, Dogaru C, Ellis F. Hear Me. Believe Me. Respect Me. A Survey of Adult Survivors of Child Sexual Abuse and Their Experiences of Support Services. Healthwatch England, 2015 (http://cdn.basw.co.uk/upload/basw_122305-1.pdf).

20 Scottish Executive. The Report of the Scottish Executive Short-Life Working Group on the Care Needs of People Who Have Survived Childhood Sexual Abuse. Scottish Executive, 2017 (http://fbga.redguitars.co.uk/shortLifeReport. pdf)

21 McNeish D, Scott S. Mental Health Trusts Collaboration Project. Meeting the Needs of Survivors of Abuse - Overview of Evaluation Findings. DMSS Research \& Consultancy, 2008 (https://www.dmss.co.uk/pdfs/mental-health-trusts-collaboration-project.pdf)

\section{psychiatry in history}

\section{James Boswell: the Hypochondriak, his melancholy, and Dr Johnson's cognitive-behavioural remedy}

\section{Greg Wilkinson}

James Boswell, 9th Laird of Auchinleck (1740-1795), advocate, essayist (The Hypochondriak), diarist and biographer, is best known for The Life of Samuel Johnson (1791), which is considered to be the greatest biography in English. Boswell suffered from recurrent depressions. He had a strict and emotionally deprived childhood. He was unhappy at school and suffered from nightmares and shyness. He was afflicted by a nervous illness in 1752 and was sent to recover at Moffat spa, in Dumfries and Galloway. Midway through his studies at the University of Edinburgh (1753-1758/9), he suffered another such episode and returned to Moffat. At 19 years of age, he studied at the University of Glasgow where, despite a Calvinist and Presbyterian upbringing, he decided to convert to Catholicism and become a monk. His father ordered him home. In 1760 he ran away to London, where he spent 3 months. Pottle said 'His greedy draughts of venal pleasure had brought him that distemper with which Venus, when cross, takes it into her head to plague her votaries (another of his own elegant euphemisms), the distemper had developed into what he calls a nervous fever, and he was ill and abashed'. He was taken back to Scotland by his father. He re-enrolled at the University of Edinburgh and was forced by his father to sign away most of his inheritance in return for an allowance of $f 100$ per year. In 1762 , he passed his oral law exam, after which his father raised his allowance to f200 per year and permitted him to return to London. On 16 May 1763, he met Johnson, and they subsequently became friends.

Boswell wrote to his friend Temple:

Again there has been a sad interval in our correspondence. But do not blame me. I have had a pretty severe return this summer of that melancholy or hypochondria, which is inherent in my constitution and from which I have suffered miserably in former years, though since my marriage I have been wonderfully free from it. Your languor and discontent are occasioned by a gentler species of the distemper. You have a slow fever, I a raging one. While gloomy and fretful, and grossly indolent, I was shocked with the recollection of my good spirits, gayety, and activity, as a man with a headache is shocked by bright sunbeams. - But I need not describe my feelings to you. - The strange thing was that I did not write to you, a few lines, merely as firing guns of distress. Nobody here but my wife and worthy Johnson had the least notion of my being at all uneasy; for I have been remarkably busy this summer. I wrote about threescore law-papers, and got f124 in fees during last sessions two months. The court rose yesterday; and this day the clouds began to recede from my mind; I cannot tell from what cause.

And he tells us in his Journal:

I complained to $\mathrm{Mr}$. Johnson that I was much afflicted with melancholy, which was hereditary in our family. He said that he himself had been greatly distressed with it, and for that reason had been obliged to fly from study and meditation to the dissipating variety of life. He advised me to have constant occupation of mind, to take a great deal of exercise, and to live moderately; especially to shun drinking at night. 'Melancholy people,' said he, 'are apt to fly to intemperance, which gives a momentary relief but sinks the soul much lower in misery.' He observed that labouring men who work much and live sparingly are seldom or never troubled with low spirits. It gave me great relief to talk of my disorder with Mr. Johnson; and when I discovered that he himself was subject to it, I felt a strange satisfaction which human nature feels at the idea of participating distress with others; and the greater person our fellow sufferer is, so much the more good does it do us. 